\title{
Salutogenic Design: Interactive Children Healthcare
}

\author{
Razqyan Mas Bimatyugra Jati \\ Architecture Design, \\ Department of Architecture, \\ Institute of Technology Sepuluh Nopember \\ Kampus Sukolilo Surabaya 6011, Indonesia. \\ Perumahan Bumiasri Sengkaling Blok G-18, \\ Malang and 65151, Indonesia
}

\author{
Muhammad Faqih \\ Department of Architecture, \\ Institute of Technology Sepuluh Nopember \\ Kampus Sukolilo Surabaya 6011, Indonesia
}

\author{
Sri Nastiti Nugrahani Ekasiwi \\ Department of Architecture, \\ Institute of Technology Sepuluh Nopember \\ Kampus Sukolilo Surabaya 6011, Indonesia
}

\begin{abstract}
This present research deals with the way to design children healthcare using an interactive approach to designing which is in line with pediatric patient behavior. Pediatric patient behavior should be accommodated in designing a children healthcare to facilitate their healing process. Therefore, it is necessary to conduct a research on the characteristics of healing behavior and approach to patients in order to obtain design criteria. The designing of the whole building elements referred to the design criteria in the form of and their environment on the basis of the salutagenesis theory and pediatric patient behavior.
\end{abstract}

Keywords: Pediatric Patient Behaviour, Salutogenesis, Interactive.

\section{INTRODUCTION}

\section{A. Research Background}

Architecture may influence life quality, comfort, healing period, treatment level, sleeping pattern and patient behavior in health facility [1]. In designing a children health facility, patient characteristics should be paid attention in order to help the patient healing process. Pediatric patients will feel stressful when they themselves do not understand the situation they face, when they feel that they lose control of themselves, or when they are thinking that some (harmful) changes will happen to their bodies [2]. Such a loss of control may result in the feelings of fright, anxiety, sadness, loneliness and longing that may give negative effects on their physical and mental condition [3]. Therefore, it is necessary to design a children healthcare with the approach to the mental healing of pediatric patients.

Patient mental healing may use a salutogenesis theory. The theory deals with psychological aspect of the patient by changing the focus of healing attention on humans (patients) instead of their diseases [4]. There are three aspects in the theory translated into some keywords into an architectural approach namely comprehensibility, manageability and meaningfullness [5]. The design of children healthcare with the salutonegesis approach will deal with the translation of the psycho-social and psychoenvironmental aspects into architectural elements [6].

The two aspects principally concern with how the elements in a children healthcare building may support the interactions between patients and their environment. Some designing elements in the building elements that may support the interactive concepts are among others the arrangement of the furniture and space, shapes, colors, and materials. So that the application of such an interactive designing in the children healthcare may help the pediatric healing process.

\section{B. Research Location}

The research location was divided into two types based on the research on the pediatric patient behavior and the children health facility design. For the research aspect of behavior, it was conducted in Darmo Children Center (Jalan Raya Darmo No. 90, Surabaya, Indonesia), considering that it understand characteristics of pediatric patients when the patients were in the healthcare facility, whereas for the aspect of design of the children healthcare facility, it was made in dr. Soetomo General Hospital (Jalan Mayjend Prof. Dr. Moestopo No. 6-8, Surabaya Indonesia) with the with the consideration that this healthcare facility had supporting the existing health facility in in order to accelerate the healing of the pediatric patients [Fig. 1].

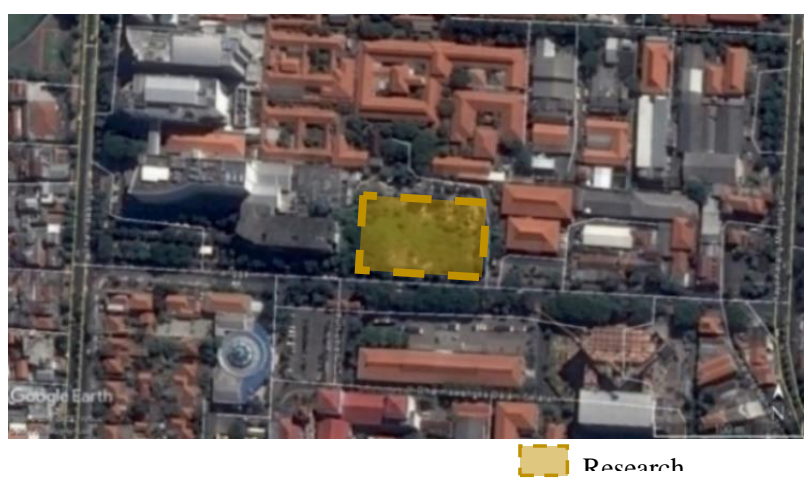

Fig. 1. Map of Study Area 


\section{A. Salutogenic Design}

\section{LITERATURE REVIEW}

Salutogenic design is an approach to design based on the salutogenesis theory in the health science. This theory deals with psychosocial studies trying to keep the state of wellbeing with the view that disease and health are different but they are in the same continuum and each is influenced by Generalised Resistance Resources (GRRs) and Generalised Resistance Deficits (GRDs) [5].

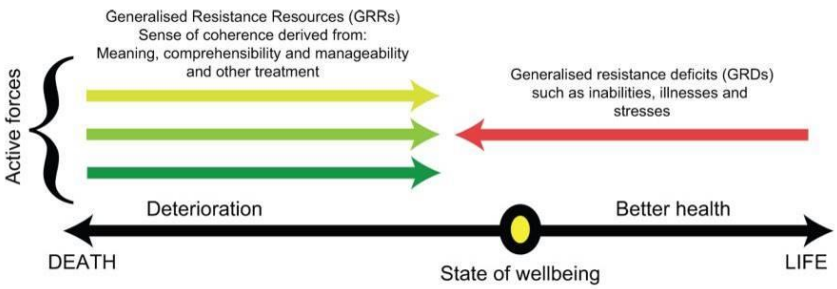

Fig.2 The salutogenic effect

Source: Golembiewski, J. (2010)

An important focus of this theory is the translation from GRR into the sense of coherence (SOC) as the realization of an opposition to GRD to get better health [Fig. 2.]. SOC has some elements if it is translated into elements of architecture, namely:

a) Comprehensibility: it ascertains that the perception raised help the patient perception process. It may be done by showing textures and materials used, controlling the size of the rooms and the number of patients and expressing the environmental features normally.

b) Manageability: it gives chances to the patients to make some control over themselves comprehensively and independently that may be made by giving access to the windows, some common activities and access to sport facilities..

c) Meaningfulness: it improves the environmental values to the patients that may be done by providing rooms full of aesthetic values and memorable things through personal stuffs and even providing rooms that may facilitate interactions with other creatures (plants and animals.

Salutogenic design possess some factors that should be considered in designing something dealing with psychosocial aspects [7]. The factors that should be considered to support the psycho-social aspects are among others (a) access to symbolic and spiritual elements, (b) access to arts (c) proper lighting, (d) rooms facilitating social interactions (e) availability of private rooms, (f) interior environment providing positive experiences $(\mathrm{g})$ visual \& physical access to the nature (h) patients that may personal (independent) control (i) natural light (j) sound and (k) inner room with coherence.

\section{B. Behaviour Architecture}

Behavior is one's reaction or response to any stimulus from others. The process of the existence of reaction or response is some stimulus to the organism and then the organism give reactions or responses, and it is usually called S-O-R (Stimulus-Organisme-Respons) theory [8]. The stimulus given by an architecture that may result in some response in the form of behavior shown by the users of the architecture is called affordances. Affordances will give chances of the emergence of various behaviors to the users in using the object of the architecture [9].

\section{Characteristics of Pediatric Patients}

When pediatric patients are examined, they will show some attitudes: (a) cooperative, (b) uncooperative, (c) hysterical , (d) stubborn, (e) shy, (f) tense, and (g) sentimental. Factors that may influence the patient behavior during the treatment deal with the range of ages and the number of patients coming to the hospital. Moreover, interactions and relations between the medical staffs and members of family of the patients may also influence the patients in the hospital.

Pediatric patients are susceptible to stress, and this may influence the healing process of the patients. The causes of the stress are that that they are from their family and friends, they feel uncomfortable or painful, there are some changes in the shape or image of their bodies, they should experience a lot of tests to diagnose their diseases, they experience surgeries, anesthesia, and treatments, they meet something strange to them, they should contact with a strange environment related to senses (heat, glare, noise) they are afraid to obey the rules or agenda of therapies in the hospital, they lose their freedom from daily activities and they have less privacy [2][3]. By using therapeutic playing methods such as puzzle, lego, drawing, folding and telling in the patient healing process, the level of anxiety and stress of the pediatric patients may be reduced [10].

\section{Interactive Approach to Children Healthcare}

In designing children healthcare facility that may give effects on their healing process, it is necessary to organize architectural elements that may facilitate the active interactions between the patients and their environment. an interactive approach may be made by arranging rooms in such a way that they form socio-petal spaces, and create various shapes, colors, and materials to support the patient tactile aspects and give a situation that may make the patients be as if in a playground. Elements of the building that should be paid attention in designing a children healthcare facility are as follows (1) the exterior may give positive impression to the patients, (b) the interior (waiting rooms and patient rooms) may support patients' social interactions, (d) the light (natural or man-made) may give a positive situation to the patients, and (e) the colors and the materials are various and the scale of the rooms and furniture should pay attention to the comfort and safety of the patients [11].

\section{METHODOLOGY}

In designing Interactive Children Healthcare (ICH), two methods were adopted, namely the research method to collect the data and the designing method to develop the design.

\section{A. Research Method}

In this present research, two approaches were adopted, namely deductive and inductive. In the deductive research, a literature searching strategy dealing the health building for children, salutogenesis patient healing theory and pediatric 
patient behavior was used. While for the inductive research, a qualitative research strategy was adopted by directly studying pediatric patient behavior realistically [12].

The research aspects principally dealing with the architectural psychology are behavior and behavior shaper. The research object and population were pediatric patients, patient family, nurses and doctors in Darmo Children Center (DCC). In this qualitative research, the data were collected through the the techniques of observations, interviews, questionnaires, and documents (pictures)

\section{B. Design Method}

A force-based method was employed in the design method, namely activities of designing using non formal factors out of the architecture discipline based on the quality or requirements intended to reach in design [13]. This forcebased method has a series of main frameworks:

(a) context/culture/needs - identify force: looking form factors that may influence problems of design dealing with patient behaviour,

(b) propose forms: formulating the relation between the quality/requirement of each element of design and the design field to result in a design concept based on the requirements determined in the previous framework,

(c) refine and assemble system: finishing and assembling the system (the relations among design elements) to result in a comprehensive building performance and dan

(d) proposal: a comprehensive proposal in the form of a schematic building design.

\section{RESULTS AND DISCUSSION}

The result results deductively and inductively serve as design criteria as the design manual. The design criteria are divided into the interior and exterior building areas. The interior building area consists of waiting and therapy rooms, the exterior building area deals with the building appearance.

The consideration in dividing the area is related to the space and elements in the building with high interaction intensity with pediatric patients. The design criteria serving as the manual in designing the ICH (Interactive Children Healthcare) are among others:

A. Waiting Room

- It has an atmosphere like in the playground,

- It minimizes inter room visual dividers,

- It is a playground that may be accessed from all directions and by all users (patient family, nurses and patients),

- It is close with administrative room, waiting rooms and the playground,

- There are educational ornaments (reading books, ornaments of the nature) grouped according to the age level,

- The arrangement and choice of the furniture are arranged according to the children scale to 17 year old children,

- The materials of the floor and wall give security and safety (warm and not hard and not sharp)

- There is a different level of the floor in the playground,
- There are different materials in the wall or the floor that may support patient tactile ability,

- Warm and cheerful colors are used to build patient mood,

- It accommodate various playing instrument form children,

- The room scale give some impression of freedom .
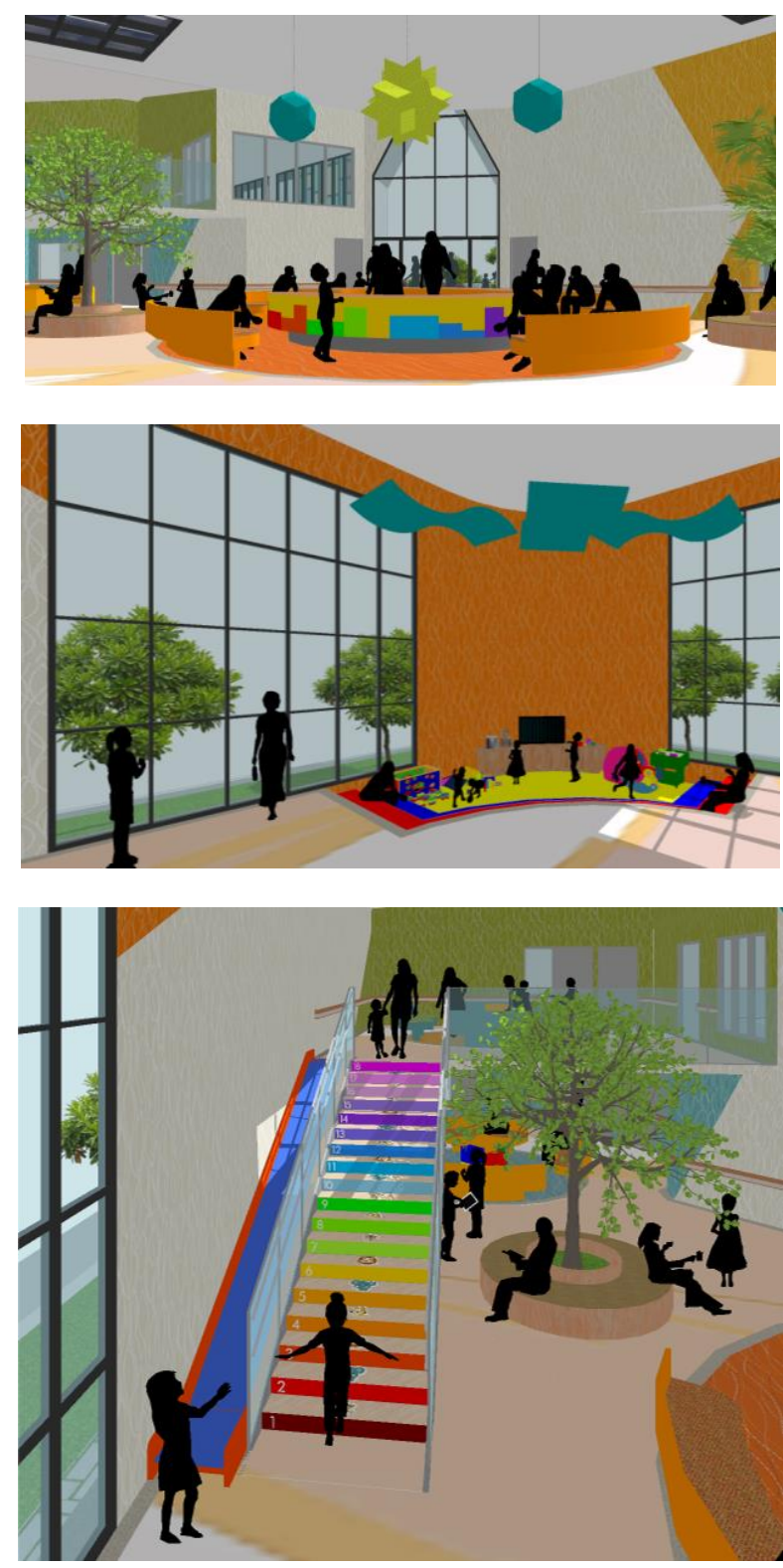

Fig. 3 The atmosphere of the Waiting Room 

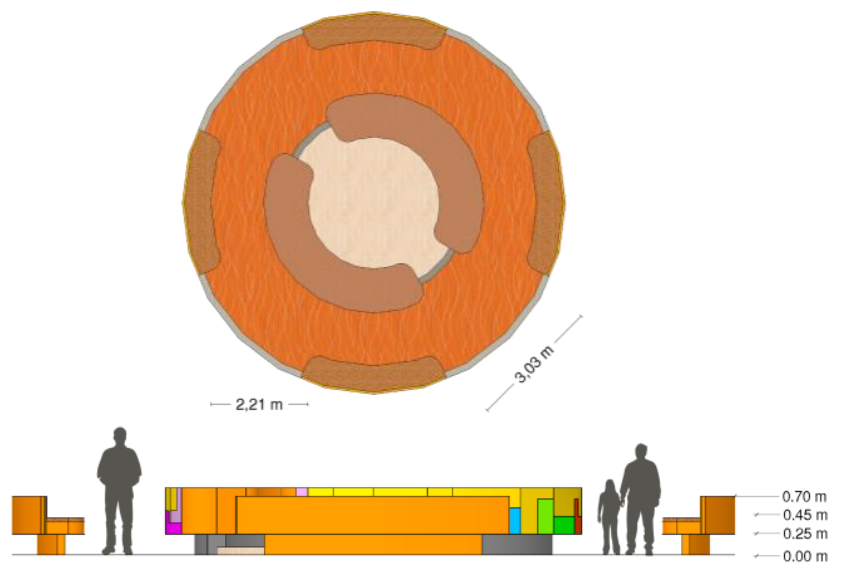

Fig. 4. Seats in Waiting Room

The use of the artwork ornaments in the ceiling with $6 \mathrm{~m}$ high, various colors in the ladder area by adding gliding boards give an impression of a certain atmosphere in the socio-petal spaces-based waiting room with cyclic geometrical shape [Fig.4]. The seats are oriented into the receptionist. The social distance is $1-3 \mathrm{~m}$ in the seat arrangement. The height of the seat depends on the ergonomy of the pediatric patients namely $0.4 \mathrm{~m}$.

\section{B. Therapy Room}

- The atmosphere of the room may improve the pediatric patient concentration,

- It minimizes the form and the ornaments that may result in distractions to the patients,

- The materials of the floor and the wall give security and safety (warm and not hard and not sharp \&,

- The use of colors may improve the pediatric patient concentration,

- The scale of the room may give an impression of closeness,

- The place of the therapy may be accessed visually from the outside to the inside room,

- The acoustic process may help improve the pediatric patient concentration,

- The furniture is arranged in such a way that it may accommodate the instruments of the therapy (puzzle, balls, and sway,

- The room may accommodate the users in arranging the room independently to create a certain atmosphere in terms of color, ornaments, light and temperature.
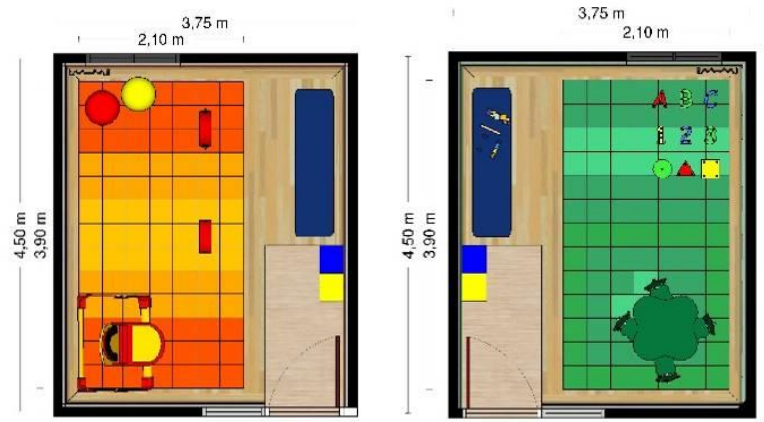

Fig. 5. Therapy Occupation (a) \& Therapy Speech (b) Room Plan

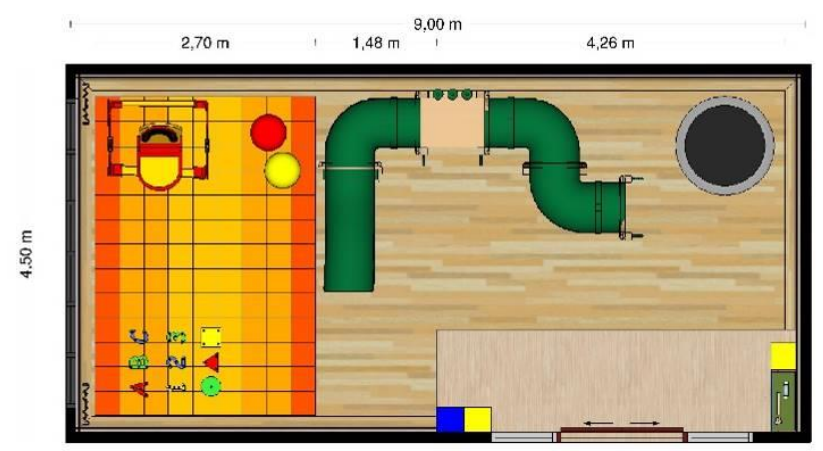

Fig. 6. Therapy Observation Room Plan

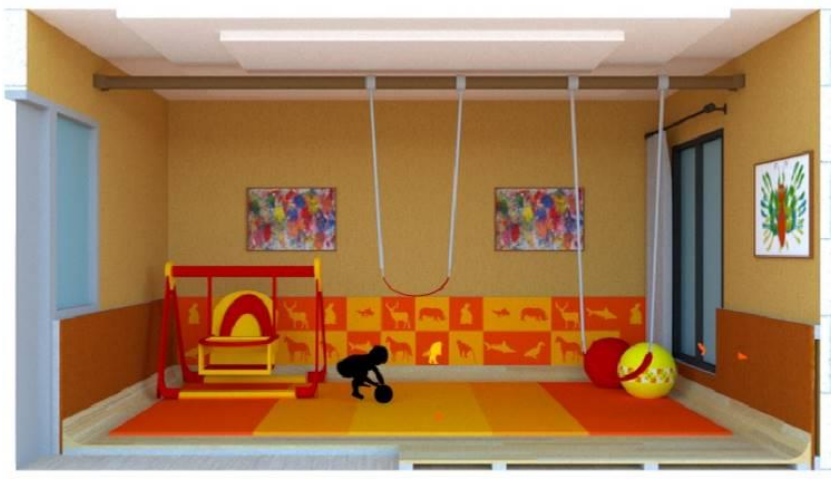

Fig 7. Therapy Occupation Room

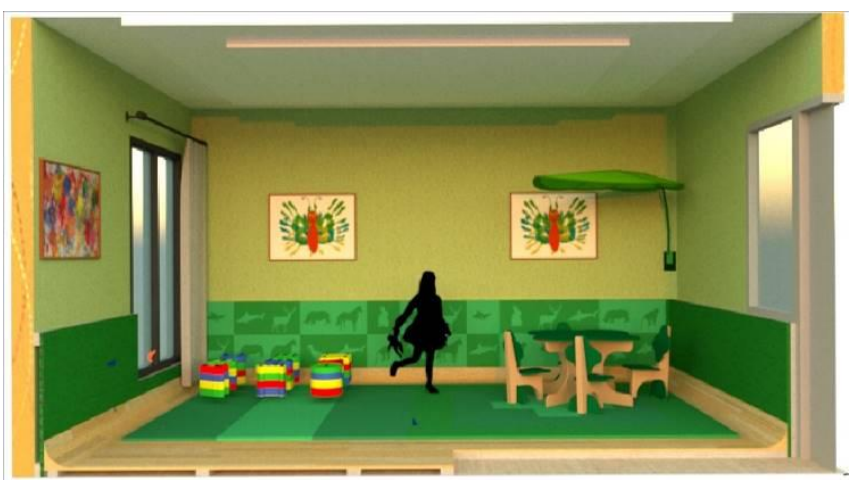

Fig 8.Therapy Speech Room

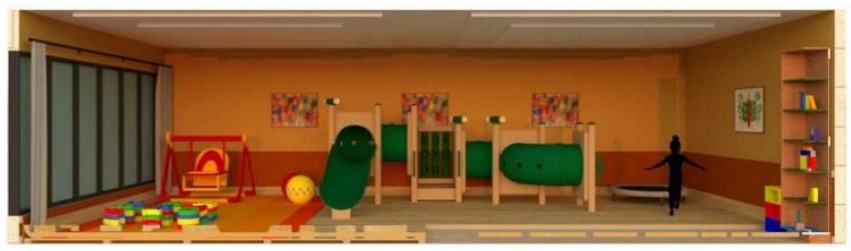

Fig 9. Therapy Observation Room

The materials of the wall are made from rubber and plastics which are not hard and may serve as the the media of therapy. The difference of the materials and of height of the floor level of $4 \mathrm{~cm}$ serves as the response to the patient behavior when they have therapy. The slope of the floor to the angle of the wall is intended to give some safety and security to the patients. The $2.55 \mathrm{~m}$ ceiling is intended to create a room scale with the impression of close. The bright color in each element of the therapy room is intended to improve the patients' concentration during the therapy. 


\section{Building Appearance}

- Building appearance gives characteristics of children healthcare building,

- The use of various colors may give positive mood/impressions to the patients,

- It gives an impression as if it is a playground form the patients.

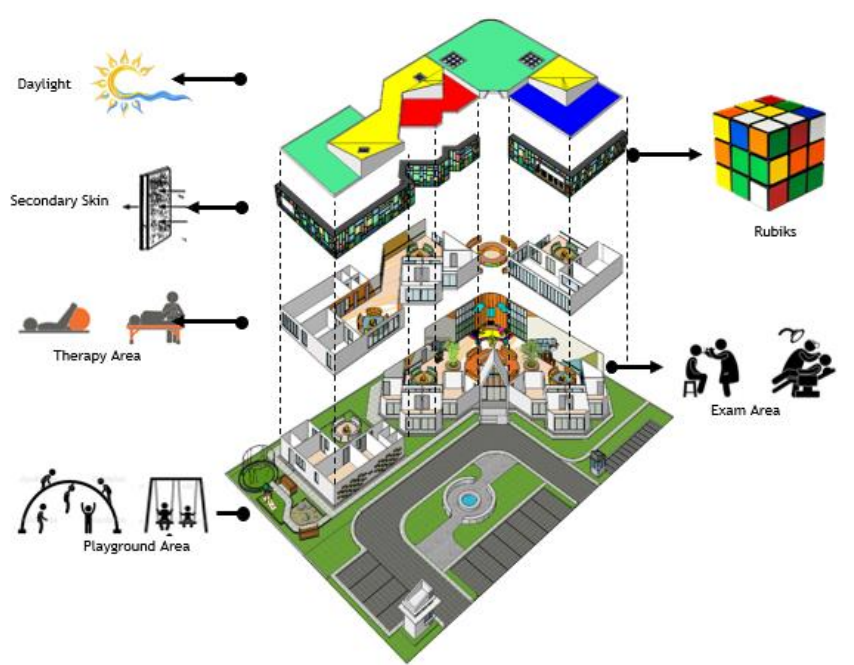

Fig 10. Concept of Interactive Children Healthcare
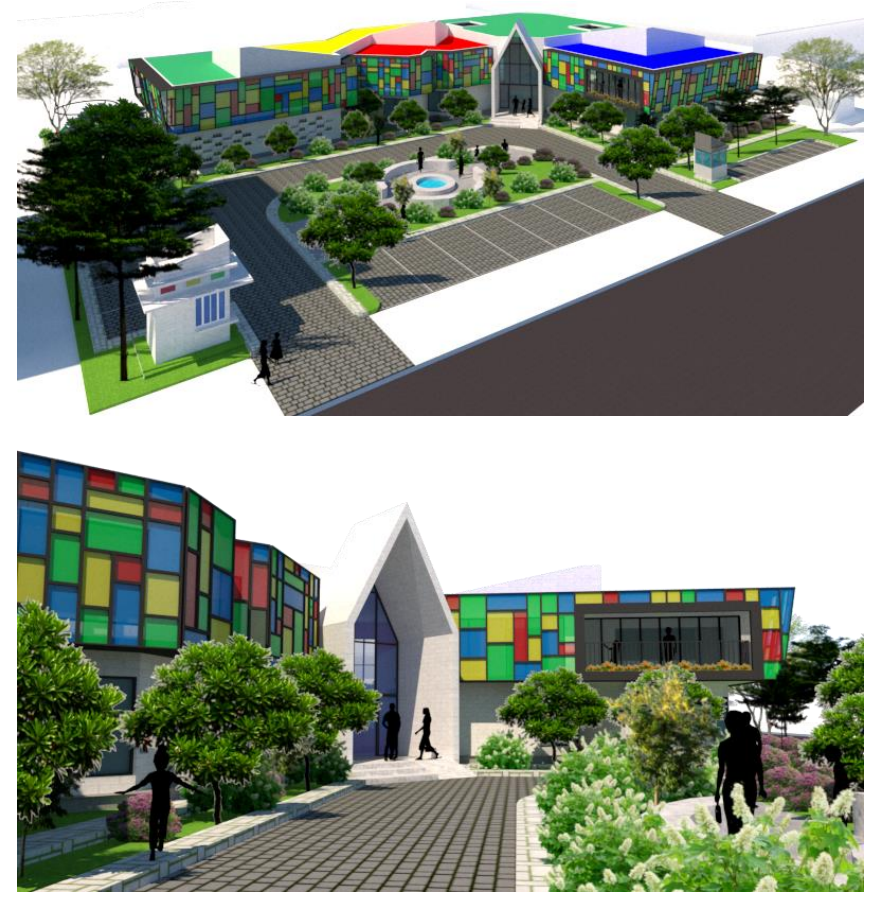

Fig. 11. Appearance of Interactive Children Healthcare

The building appearance with mosaic motif refers to the appearance of rubric games with the application strategy in the building secondary skin [Fig. 10]. The Processing of the scale and shape in the entrance area give positive impressions to the pediatric patients. The diversity of colors and shapes in the ceiling area and cover gives an atmosphere like a playground [Fig 11].

\section{V.CONCLUSION}

This design answers the implementation of the design of the healthcare building based on the behavior of the user namely pediatric patients. An interactive approach referring to the salutogenic design is adopted as the strategy of the implementation. The use of the socio-petal spaces, the diversity of shapes, colors and materials, the atmosphere of the building like a playground may give an active interaction to the pediatric patients so that it may accelerate the healing process of the patients..

\section{REFERENCES}

[1] Lawson, B. (2010). "Healing Architecture". Arts \& Health: An International Journal for Research 2010.

[2] Menke R.N. Edna. (1981). "Schooled-aged Children's Hospital of Stress in the Hospital".

[3] Lambert, Veronica, Jane Coad, Paula Hicks \& Michele Glacken. (2013). "Young children's perspectives of ideal physical design features for hospital-built environments". Ireland: Journal of Child Health Care 2014.

[4] Antonovsky, A. (1996). "The salutogenic model as a theory to guide health promotion". Health Promotion International.

[5] Golembiewski, J. (2017). "Salutogenic Architecture in Healthcare Settings". The Handbook of Salutogenesis, Chapter 26, 267-276.

[6] Golembiewski, J. (2010). "Start making sense: Applaying a salutogenic model to architectural design for psychiatric care". Facilities, 28 (3/4), 100-117.

[7] Dilani, A. (2008). "Psychosocially Supportive Design: 7A Salutogenic Approach to the Design of the Physical Environment". International Conference on Sustainable Healthy Buildings; Seoul, Korea.

[8] Notoatmodjo, oekidjo. (2003). Pendidikan Dan Perilaku Kesehatan. Jakarta: Rineka Cipta.

[9] Laurens, J. M. (2004). Arsitektur Perilaku Manusia. Grasindo: Jakarta.

[10] Sulianti, Ambar (2016). "Pendekatan Bermain Untuk Menurunkan Perilaku Menghindar Pada Anak yang Mengalami Trauma Pengobatan”. Psympathic, Jurnal Ilmiah Psikologi Juni 2016 Vol. 3, No. 1, 113-120.

[11] Kyrkou, A. \& Vavili, F. (2014). "Innovative Materials In Children's Hospital Design”. Conference Paper August 2014.

[12] Groat, Linda N. And Wang, David (2013). Architectural Research Methods. John Wiley \& Sons Inc., New Jersey.

[13] Plowright, P. D. (2014). Revealing Architectural Design: methods, frameworks and tools. Routledge., New York. 